\title{
Single-visit endodontic treatment of mature teeth with chronic apical abscesses using mineral trioxide aggregate cement: a randomized clinical trial
}

\author{
Reem Siraj Alsulaimani
}

\begin{abstract}
Background: Mature teeth with chronic apical abscesses characterized by intermittent discharge of pus through an associated sinus tract. This communication between oral mucosa and periapical inflammation is challenging for the sealing ability of root canal obturation material. Therefore, the study aim was to compare the outcomes of endodontic treatment using mineral trioxide aggregate (MTA) cement to the conventional gutta-percha cone and root canal sealer as an obturation material in mature teeth with chronic apical abscesses.

Methods: Mature teeth with chronic apical abscesses referred to our clinic for root canal treatment between 2010 and 2012 were treated in a single visit and distributed among treatment (T) and control (C) groups using a predetermined randomization block (TCTC). After chemo-mechanical preparation, teeth in group T received MTA cement mixed in a 0.26 water to powder ratio, and teeth group $C$ received gutta-percha and root canal sealer using the warm vertical technique. The treatment outcomes were defined as obturation length, periapical healing, resorption of extruded material, and survival rate at least 2.5 years after treatment. Three endodontists blinded to the type of obturation material documented treatment outcomes. Statistical analysis at $P<0.05$ was conducted to measure difference between the groups.
\end{abstract}

Results: Thirty-six teeth were treated between 2010 and 2012, and 32 teeth were evaluated in 2015. Complete periapical healing was observed in $87.5 \%$ of MTA-treated teeth and $75.0 \%$ of gutta-percha-treated teeth. Adequate obturation length was reported in $50.0 \%$ of MTA-treated and $37.5 \%$ of gutta-percha-treated teeth. Complete resorption of extruded material was evident in $83.3 \%$ MTA-treated teeth and $100.0 \%$ gutta-percha-treated teeth. The survival rate of MTA-treated teeth was $100 \%$ at 3, and 5 years, while the survival rate of gutta-percha-treated teeth was $83.3 \%$ at 3 , and 5 years. There was no significant difference between the groups in term of periapical healing, survival rate, obturation length, or resorption of extruded material.

Conclusions: The outcomes of single-visit endodontic treatment of mature teeth with chronic apical abscesses using MTA cement were better, but not statistically significant, compared to conventional treatment.

Trial registration: ISRCTN15285974. Registered retrospectively 23 June 2015.

Keywords: Single visit, Periapical lesion, Mineral trioxide aggregate, Root canal treatment

Abbreviations: MTA, Mineral trioxide aggregate; WP, Water to powder ratio

Correspondence: dr.ralsulaimani@gmail.com; reem@ksu.edu.sa

Lecturer in the Department of Restorative Dental Science, College of

Dentistry, King Saud University, P.O. Box 60169, Riyadh 11545, Kingdom of

Saudi Arabia 


\section{Background}

A chronic apical abscess is a long-standing periapical inflammation characterized by intermittent discharge of pus through an intraoral sinus tract, with radiolucent signs of periapical osseous destruction [1]. Several studies reported that the prevalence of mature teeth with chronic apical abscesses ranges between $9.7 \%$ and $18.1 \%[2,3]$. In general, the presence of direct communication between the oral mucosa and periapical inflammation is challenging for the sealing ability of root canal obturation material.

Special treatment of chronic apical abscesses such as, sinus tract cauterization or surgical apicoectomy have been advocated by earlier report $[4,5]$, while others have described the complete healing of sinus tracts with nonsurgical endodontic therapy $[6,7]$. The literature shows scarce case reports on the treatment of mature teeth with chronic apical abscesses. These reported treatments have ranged from multiple-visit treatment with intracanal medicament to single visit treatment [8-10], without special consideration to the communication present between the oral mucosa and periapical inflammation.

After chemo mechanical preparation, the primary goal of root canal obturation is to prevent the spread of bacteria and bacterial toxins from the canals into the periapical tissues [11]. Furthermore, since obturation material comes into contact with periodontal tissue, it should not interfere with periapical tissue healing; preferably, it should stimulate periapical tissue regeneration [12]. The conventional root canal obturation material consist of gutta-percha cones and root canal sealer. The biocompatibility and sealing ability of gutta-percha cones and root canal sealer was reported to be less than Mineral Trioxide Aggregate (MTA) cement [13, 14]. Moreover, teeth with significant periapical pathosis, such as chronic apical abscesses, are future candidates for surgical intervention, and Mineral trioxide aggregate (MTA) cement is the recommended retrograde filling material [15].

Therefore, the study aim was to compare the outcomes of endodontic treatment using mineral trioxide aggregate (MTA) cement to the conventional gutta-percha cone and root canal sealer as an obturation material in mature teeth with chronic apical abscesses.

\section{Methods}

\section{Study population}

Those patients referred to the endodontic clinics at Girls University Campus, College of Dentistry, KSU between 2010 and 2012 were screened for teeth diagnosed with chronic apical abscesses. For this study, the inclusion criteria included restorable teeth with closed apices, visible sinus tracts, and periapical radiolucency with diameters larger than $3 \mathrm{~mm}$ (Fig. 1b). Forty-one teeth
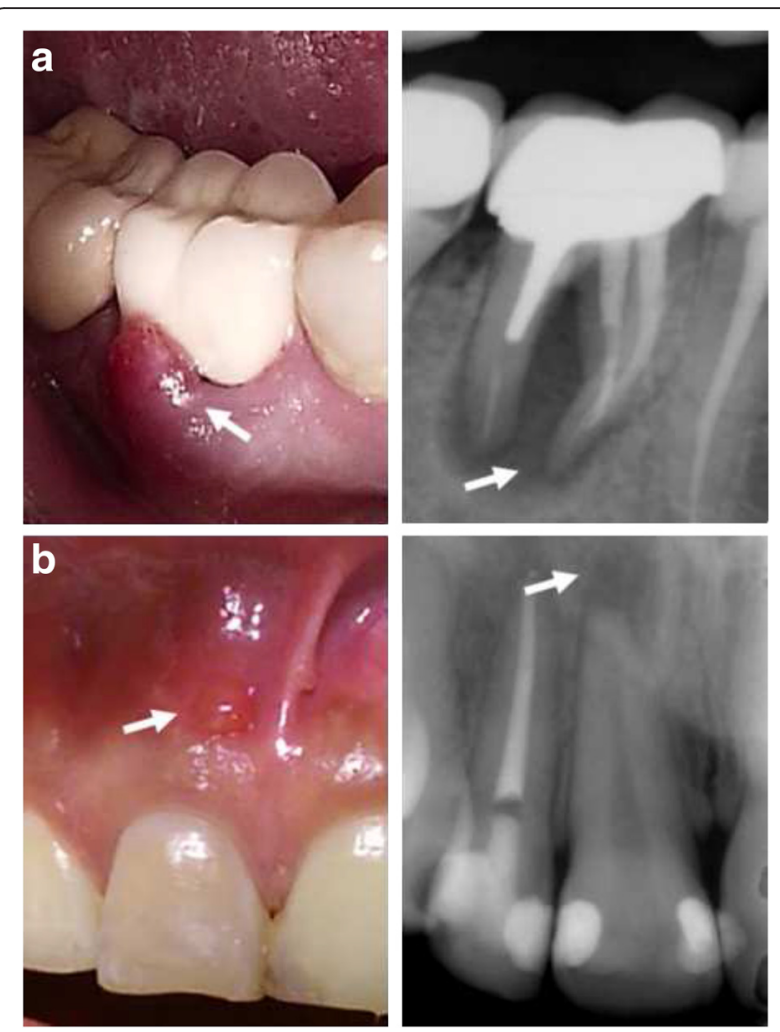

Fig. 1 Clinical and radiographical presentation of mature teeth with chronic apical abscesses. a Non-restorable tooth with sinus tract and periapical radiolucency (arrow) excluded from the study. b Restorable tooth with sinus tract and periapical radiolucency (arrow) included in the trial

were screened, and five were rejected because they did not satisfy the inclusion criteria (Fig. 2).

In total, 36 teeth were enrolled in this trial. A sample size of at least 16 teeth in each study group was determined to be sufficient to detect an assumed clinically significant difference of $43 \%$ in periapical healing between the treatment $(\mathrm{T})$ group using MTA cement and the control $(\mathrm{C})$ group using gutta-percha cone and root canal sealer. This study adopted a two-tailed chi-squared test with $90 \%$ power and a $5 \%$ level of significance.

\section{Study design and treatment materials}

The included teeth were allocated among $\mathrm{T}$ and $\mathrm{C}$ groups using a 1:1 ratio in a parallel design, and the clinical staff assigned teeth using a predetermined randomized block (TCTC). Teeth with history of root canal treatment were labeled as secondary treatment and distributed evenly among the $\mathrm{T}$ and $\mathrm{C}$ groups. Moreover, the patients were blinded to the type of obturation material.

The single-visit endodontic treatment was performed under local anesthesia using rubber dam isolation and 3.5x magnification. The coronal access cavity was prepared and, 


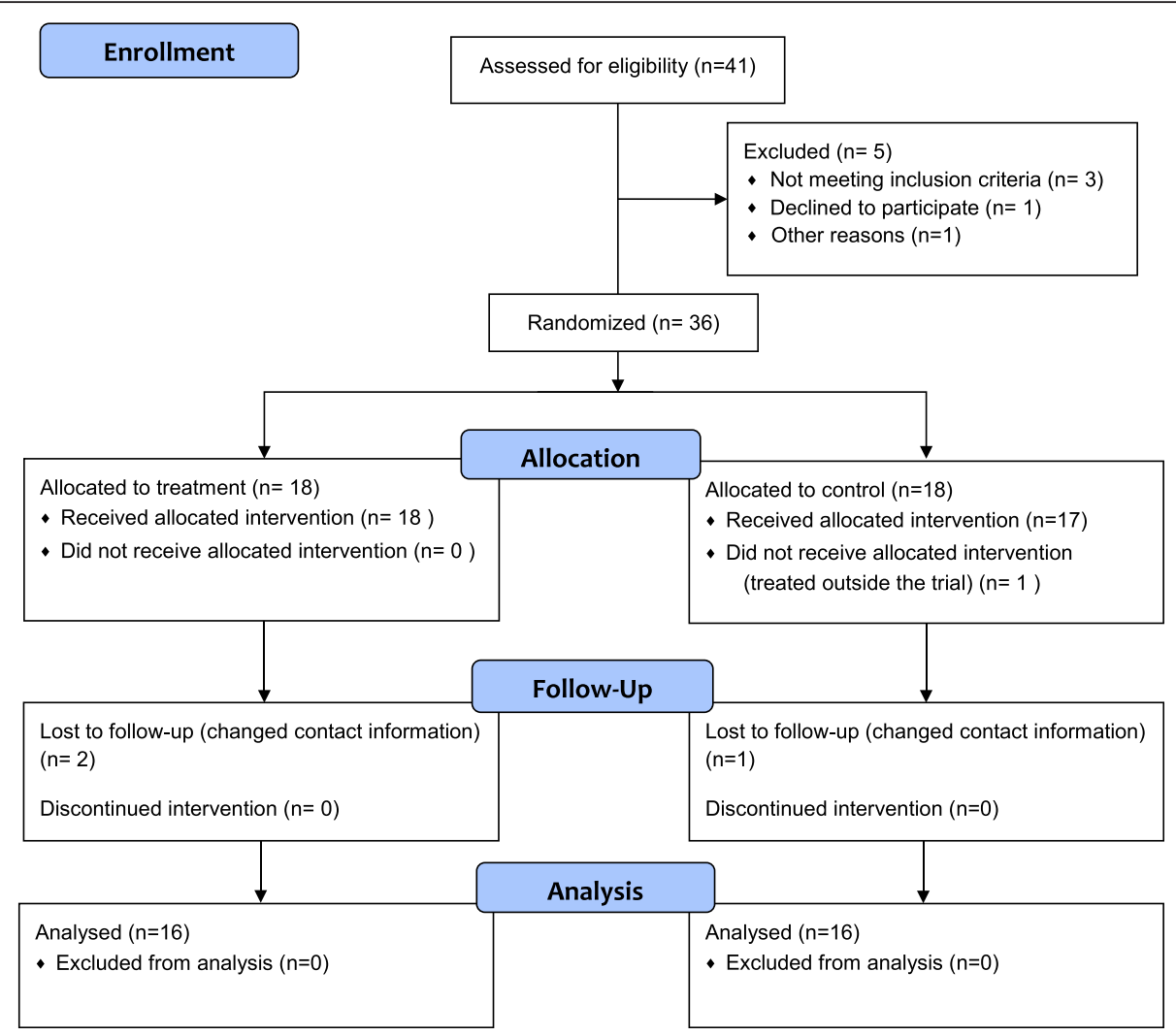

Fig. 2 CONSORT flowchart of patients enrolled in the study

when required, the previous root canal filling was dissolved using chloroform, then, the radicular space was cleaned and shaped using RaCe rotary NiTi files with 0.04 and 0.06 tapers (FKG Dentair, La Chaux-de-Fonds, Switzerland). Irrigation protocol consisted of $5 \mathrm{ml}$ of $5.25 \%$ sodium hypochlorite $(\mathrm{NaOCl})$ during root canal shaping, and saline prior to root canal obturation. The working length was determined using a Root ZX apex locator (J. Morita Mfg. Corp., Kyoto, Japan). Canal shaping was considered to be adequate when the apical preparation was at least $0.35 \mathrm{~mm}$ for primary treatments and $0.50 \mathrm{~mm}$ for teeth with secondary treatments.

The teeth in group $\mathrm{T}$ were filled with $4 \mathrm{~mm}$ of White ProRoot $\mathrm{MTA}^{\circ}$ (Dentsply International) mixed with sterile water in a $0.26 \mathrm{WP}$ ratio. Then, a small amount of MTA cement was applied using a dry ISO-standardized paper point (Meta Dental Corp., Chungbuk, Korea; Fig. 3a). The size of the paper point was chosen to coincide with the size of the apical preparation to compact the MTA cement at the root canal apex. In addition, the sizes of the paper points were increased (Fig. 3b) with an increasing coronal taper of the canal, and each increment used new, dry paper points until the planned obturation length was achieved.
The teeth in group $\mathrm{C}$ were filled with $4 \mathrm{~mm}$ of guttapercha and root canal sealer using warm vertical compaction. Briefly explained, the apical third was filled by down-backing a 0.04 taper gutta-percha cone with an apical diameter coinciding with the diameter of the prepared canal and coated with root canal sealer (Tubliseal Xpress canal sealant, SybronEndo. Orange, CA, USA). The micro-CT analysis to evaluate the resulting obturation densities of both techniques are presented in Fig. 3c-g.

The remaining radicular space in all teeth was either left untouched for post cementation or filled with thermoplasticized gutta-percha (Obtura ${ }^{\circ}$, SybronEndo, Orange, CA, USA), depending on the restorative plan of each tooth. Finally, the access cavity was sealed using resin-modified glass ionomer and conventional periapical radiographs were obtained after treatment completion. Every patient was referred to a restorative specialist to receive a final restorative treatment after 2 weeks.

\section{Treatment outcomes}

Periapical healing was the primary outcome and evaluated by periapical radiographs at least 2.5 years after the 


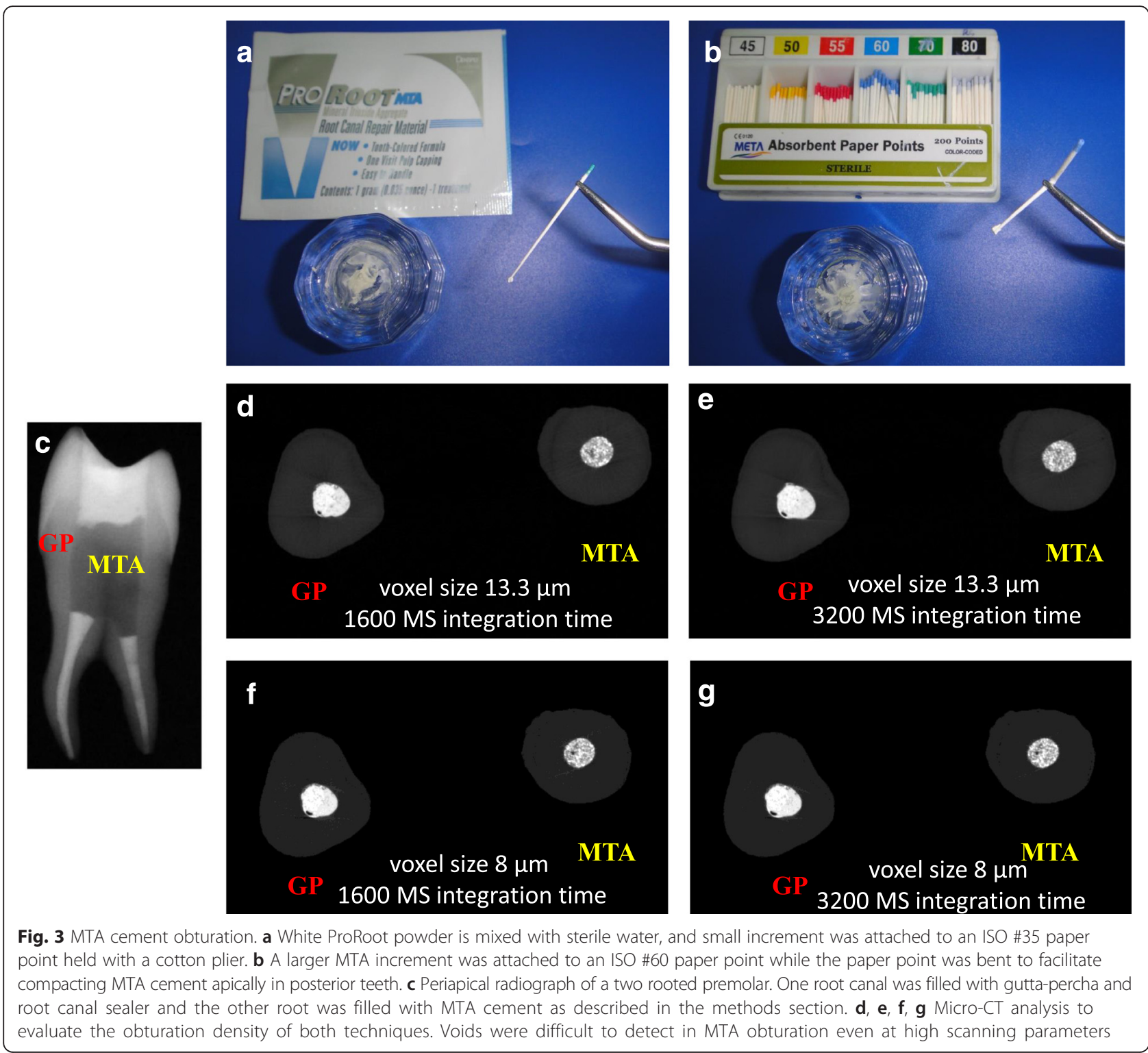

operation. Complete periapical healing was defined as a uniform width of the periodontal ligament space, no obvious breakdown of the lamina dura, and well-organized bone trabeculae [16]. The obturation length was measured using immediate postoperative radiographs, and an adequate obturation length was recognized when the obturation material ended less than $1 \mathrm{~mm}$ from the radiographic apex. Inadequate obturation was determined when the obturation ended more than $1 \mathrm{~mm}$ from the radiographic apex, and overfilling was defined as the root canal filling material extruding by more than $1 \mathrm{~mm}$ from the radiographic apex [16]. The resorption of extruded obturation material was evaluated via radiographs at follow-up visits. Overall, the obturation length and resorption of extruded material were secondary outcomes. The survival of an endodontically treated tooth was defined as its continued presence and painless function at follow-up visits [17]. To standardize the evaluations, the treatment outcomes of MTA-treated teeth were compared to gutta-percha-teeth treated during the same period of time (randomization block) during follow up visits.

Three endodontists blinded to the type of obturation material evaluated the complete periapical healing, obturation length, and resorption of the extruded material independently. In cases of disagreement, the final evaluation was based on the evaluation of two agreeable examiners.

\section{Statistical analysis}

The number and percentage of teeth with complete periapical healing, adequate obturation length, and completely resorbed extruded material were compared and 
analyzed using the chi-squared or Fisher's exact test based on the size of the data in each or total row using two-sided statistical tests and SPSS version 22.0.0. The overall survival rate was calculated at follow-up visits. In addition, the survival rate was analyzed by the history of root canal treatment using a univariate analysis and Fisher's exact test to detect significant difference between MTA-treated and gutta-percha-treated teeth. In all cases, $P$ values less than 0.05 were considered to represent a statistically significant difference between the study groups.

\section{Null hypothesis $(\mathrm{HO})$}

There will be no statistically significant difference in the number of teeth with complete periapical healing after treatment with MTA obturation, when compared with teeth treated with conventional gutta-percha cone and root canal sealer.

\section{Alternative hypothesis $(\mathrm{H} 1)$}

There will be a statistically significant difference in the number of teeth with complete periapical healing after treatment with MTA obturation compared with teeth treated with conventional gutta-percha cone and root canal sealer.

\section{Results}

Thirty-six mature teeth with chronic apical abscesses (between 2010 and 2012) were included in this study. The participants included healthy females, and their age ranging between 21 and 41 years. Thirty-two treated teeth (Table 1) were evaluated at 2015 , and the average time of follow-up was 3.6 years, with an equal distribution between study groups (Table 2).

Adequate obturation lengths were evident in eight MTA-treated teeth $(50.0 \%)$ and 6 gutta-percha-treated teeth $(37.5 \%)$ with no significant difference between the groups $(P=0.72)$. Complete resorption of the extruded material was evident in five out of six (83.3 \%) MTAtreated teeth and in eight out of eight (100.0 \%) guttapercha-treated teeth with no significant difference between the group $(P=0.42)$.

Complete periapical healing (Fig. 4) was evident in 14 out of 16 MTA-treated teeth $(87.5 \%)$ and in 12 out of 16 gutta-percha-treated teeth $(75.0 \%)$ with no statistical significant difference between the groups $(P=0.69)$. Incomplete periapical healing (Fig. 5) was observed in two out of 16 MTA-treated teeth and in two out of 16 guttapercha-treated teeth with no statistical significant difference between the groups $(P=0.69)$. Therefore, the null hypothesis was accepted.

None of MTA-treated teeth $(n=16)$ required surgical intervention or extracted at the follow-up visits; therefore, the survival rate of MTA-treated teeth was $100 \%$ at $2.5,3$, and 5 years. One gutta-percha-treated tooth was extracted at 3 years' follow-up visit, and another tooth at 5 years (Additional file 1). Therefore, the survival rate of gutta-percha-treated teeth was $100 \%$ at 2.5 years but $83.3 \%$ at 3 , and 5 years. There was no statistical significant difference between the groups at 2.5, 3 , and 5 years $(P=1,0.75,0.75$ respectively).

\section{Primary treatment vs. secondary treatment}

Table 3 demonstrates equal distribution of the primary treatments and secondary treatments among study groups. The secondary treatments for teeth with histories of root canal treatment had no significant effect on obturation length, resorption of the extruded material, or periapical healing after root canal obturation using MTA cement or gutta-percha cone and root canal sealer. At the 2.5, 3, and 5-years intervals after the treatment, there was no statistically significant difference in tooth survival between MTA-treated and gutta-percha treated teeth, when analyzed by the history of root canal treatment $(P=0.43)$.

Table 1 Summary of study sample $(n=32)$

\begin{tabular}{lll}
\hline Groups & MTA cement obturation & Gutta-percha and root canal sealer obturation \\
\hline $\mathrm{N}$ & 16 & 16 \\
Patients mean age in years with SD & $29.81 \pm 7.93$ & $32.69 \pm 8.51$ \\
Primary treatment & $8(50 \%)$ & $8(50 \%)$ \\
Secondary treatment & $8(50 \%)$ & $8(50 \%)$ \\
Maxillary teeth & $14(87.5 \%)$ & $11(68.75 \%)$ \\
Mandibular teeth & $2(12.5 \%)$ & $5(31.25 \%)$ \\
Composite build up & $05(31.25 \%)$ & $07(43.75 \%)$ \\
Crown & $05(31.25 \%)$ & $05(31.25 \%)$ \\
Crown with post and core build up & $06(37.5 \%)$ & $04(25 \%)$ \\
Survival rate & $16(100 \%)$ & $14(87.5 \%)$ \\
\hline
\end{tabular}

$S D$ standard deviation 
Table 2 Average time of follow up observed among study groups

\begin{tabular}{lcc}
\hline Obturation material & $\begin{array}{c}\text { Mineral Trioxide Aggregate cement } \\
(N=16)\end{array}$ & $\begin{array}{c}\text { Gutta-percha cone and root canal sealer } \\
(N=16)\end{array}$ \\
\hline $\begin{array}{l}\text { Follow up time (in year) } \\
\text { Mean(SD) }\end{array}$ & $3.6(1.1)$ & $3.6(1.1)$ \\
Follow up time & & Number of teeth \\
5 years & 6 & 6 \\
3 years & 6 & 6 \\
2.5 years & 4 & 4 \\
\hline
\end{tabular}

\section{Discussion}

This study is part of a randomized, double blinded, controlled trial registered as ISRCTN15285974 (http:// www.isrctn.com), with the title "Mineral trioxide aggregate (MTA) as an alternative root canal filling material". This part of the study targeted mature teeth with chronic apical abscesses because the direct communication between the periapical inflammation and oral mucosa poses challenges for the sealing ability of root canal obturation material.

Moreover, the literature does not include updated information about the management of such teeth $[6,7$,
$18,19]$, or a previous clinical trial targeting treatment of mature teeth with chronic apical abscesses. Recent publications have mainly been case reports treating mature teeth with chronic apical abscesses in multiple-visits with intra-canal medicament [9], or with the use of chlorhexidine irrigant [8], and the follow-up time was less than 2 years. Therefore, the treatment outcomes of this study cannot be compared directly to previous publications.

The practice of single-visit treatment have gained popularity due to its predictable success in term of periapical healing $[20,21]$, and satisfying patient preference

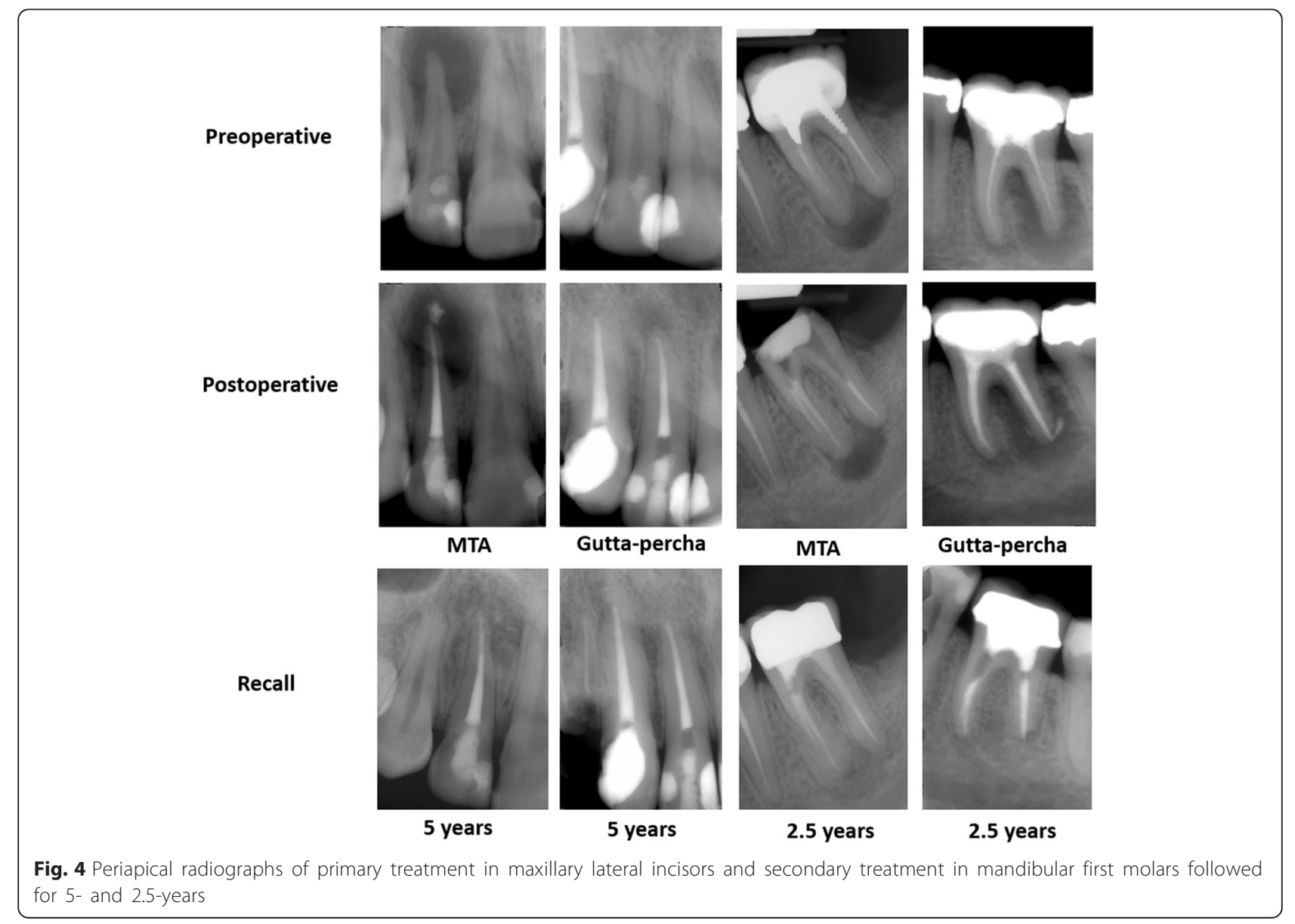




\section{Preoperative}

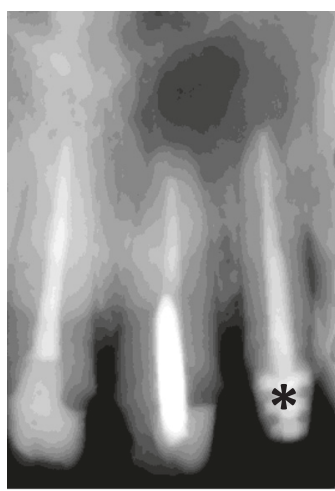

MTA

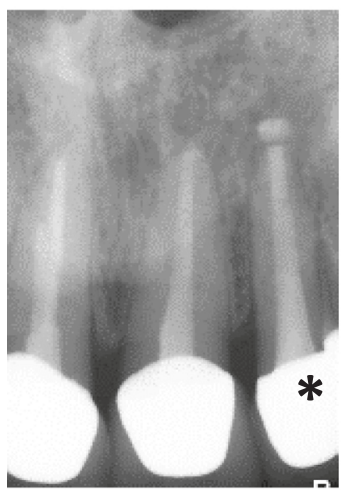

2.5 years

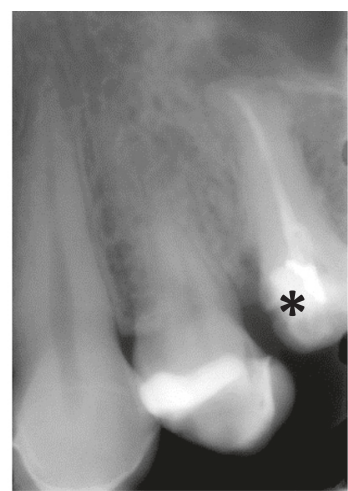

Gutta-percha

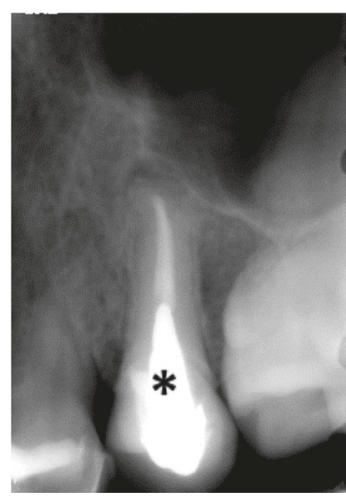

2. 5 years

Fig. 5 Periapical radiographs of MTA- and gutta-percha-treated teeth $\left(^{*}\right)$ with incomplete periapical healing at 2.5 -years follow-up visits

Table 3 Primary treatment vs. Secondary treatment

\begin{tabular}{lcc}
\hline Parameters & MTA cement obturation & Gutta-percha cone and root canal sealer obturation \\
\hline Primary treatment & $n=8$ & $n=8$ \\
Complete periapical healing & $08(100 \%)$ & $06(75 \%)$ \\
Incomplete periapical healing & 00 & 00 \\
Adequate Obturation length & $06(75 \%)$ & $04(50 \%)$ \\
Inadequate obturation length & $02(25 \%)$ & $04(50 \%)$ \\
Complete resorption of extruded material & $02(25 \%)$ & $02(25 \%)$ \\
Incomplete resorption of extruded material & 00 & 00 \\
Secondary treatment & $n=8$ & $n=8$ \\
Complete periapical healing & $6(75 \%)$ & $6(75 \%)$ \\
Incomplete periapical healing & $02(25 \%)$ & $02(25 \%)$ \\
Adequate Obturation length & $2(25 \%)$ & $2(25 \%)$ \\
Inadequate obturation length & $6(75 \%)$ & $6(75 \%)$ \\
Complete resorption of extruded material & $3(37.5 \%)$ & $6(75 \%)$ \\
Incomplete resorption of extruded material & $1(12.5 \%)$ & 0 \\
\hline
\end{tabular}


[22]. In this study, complete periapical healing was observed in $87.5 \%$ in MTA-treated, and $75 \%$ in guttapercha-treated after single-visit endodontic treatment, which is comparable to pervious reports [21]. At 5years, the survival rate of MTA-treated and gutta-percha treated teeth collectively was $91.6 \%$, which is equivalent to $92 \%$ survival rate reported in 117818 endodontically treated teeth followed for 5 years retrospectively [23].

Treated teeth were examined 2-weeks postoperatively to evaluate sinus tract healing. None of the treated teeth had a sinus tract at 2-weeks follow up. Therefore, patients were referred to a restorative specialist to receive final restorative treatment. Two gutta-percha-treated teeth were extracted due to non-restorable coronal fracture within 6 months of root canal treatment, because patients' compliance to attend restorative appointment after root canal treatment was low. Therefore, educating patients about the importance of final restorative treatment is important to maintain the functionality of endodontically treated teeth.

The primary components of MTA powder include dicalcium silicate, tricalcium silicate, and tricalcium aluminate [24]. The radiopacity of white MTA is $6.74 \mathrm{~mm}$ $\mathrm{Al}$ [25], which is adequate according to International Organization for Standardization (ISO) requirements. In addition, retreatment of MTA-filled canals after setting is possible [26]; however, the clinical manipulation of MTA cement is difficult and there is no designated instrument for orthograde obturation. In addition, root discoloration and incomplete removal of MTA cement during retreatment was reported [26]. Overall, MTA cement exhibits a superior sealing ability and biocompatibility compared to the conventional gutta-percha cones and root canal sealer [13], and an alternative root canal filling for latex-allergic patients [27].

Several attempts were proposed to facilitate MTA cement obturation in orthograde setting, including the use of Lee MTA pellet-forming block and a plugger [28, 29], ultrasonic activation [30], K-files with an apex locater as in the Lawaty technique [31] and a customized plugger for individual cases [32]. Transferring MTA cement from the mixing container into the apical third of the tooth is challenging. Because the available MTA carrier (e.g., the Dovgan MTA carrier) have a large diameter (0.8$1.6 \mathrm{~mm}$ ) that is not amenable to orthograde filling, and made of metal, therefore, the MTA cement falls out before it can be packed into the root canal. Therefore, orthograde application of MTA cement requires an instrument that coincides with the shape of the prepared root canal to facilitate transfer and compaction of MTA cement apically. Currently, such an instrument is not available.

In this study, MTA cement was mixed with a WP ratio of 0.26 as recommended by Fridland and Rosado in
2003 [33], to facilitate clinical manipulation of MTA cement. Absorbent paper points were used to transfer and pack MTA cement apically. The paper points provided the closest match to an instrument to which MTA cement attached easily and the shapes coincides with the shape of the prepared root canal. The described technique (Fig. 3) produced a radiographically acceptable obturation in MTA-treated teeth (Additional file 1); Therefore, developing MTA-carrier with the criteria noted above will facilitate MTA obturation in mature teeth.

Root canal cleaning and shaping were performed using 0.04 and 0.06 taper NiTi files, which reduced the time required for root canal preparation. In the same vein, $5.25 \% \mathrm{NaOcl}$ was used for chemical disinfection. To minimize the variables between study groups, the final irrigation before root canal obturation was performed using saline because sodium hypochlorite causes tooth discoloration when mixed with MTA cement [34], and chelating agents such as EDTA $17 \%$ or Glyde File Prep was not used because it could negatively affect the bond strengths of MTA-dentin [35, 36]. The size of the apical preparation in secondary treatment was larger than that in primary treatment to ensure removal of the previous root canal filling.

Controlling the length of root canal obturation is important from both biological and legal standpoints $[37,38]$. Every measure was taken in this study to confine the obturation material within the root canal; however, extruded obturation material was observed in 14 teeth, mainly teeth with a history of root canal treatment. Extrusion of obturation material may be explained by root resorption from chronic inflammation or alteration of the apical configuration from previous treatment attempts [39]. Nevertheless, complete periapical healing and complete resorption of extruded material was observed in 13 out of 14 teeth in the follow-up radiographs. Therefore, extrusion of some obturation material was an inevitable event, and communicating this to patients before the treatment may minimize legal disputes.

This study was limited to female patients because it was conducted at Girls University Campus and faced difficulties recruiting patients diagnosed with chronic apical abscess because patients and general practitioners tend to select extraction over endodontic treatment for teeth with chronic apical abscesses. Therefore, the eligible teeth were randomized into study blocks of 4 teeth (TCTC) to facilitate treatment of eligible teeth, rather than waiting for long period of time to collect the recommended sample size before the intervention began. Finally, the evaluation of periapical healing was limited to periapical radiographs, which are less sensitive to apical periodontitis compared with cone beam computed tomography [40]. Future studies should include larger 
sample size, long term recall period and 3D imaging modalities.

\section{Conclusions}

The outcomes of single-visit endodontic treatment of mature teeth with chronic apical abscesses using MTA cement were better, but not statistically significant, compared to conventional treatment. Mineral trioxide aggregate cement mixed in a $0.26 \mathrm{WP}$ ratio facilitated the clinical manipulation of MTA cement and compaction into the narrow and curved canals of mature teeth.

\section{Additional file}

Additional file 1: Periapical radiographs of study sample. Preoperative, postoperative, and follow-up radiographs of MTA and gutta-percha treated teeth. (PDF $583 \mathrm{~kb}$ )

\section{Acknowledgments}

The author would like to thank the College of Dentistry Research Center, King Saud University for its support (Study Registration ID: FR 0235), Dr. Mohammed Alrifaiy, BDS, Cert (Prostho), MSc, for his advice during the course of the study, Dr. Kholod Almanei, BDS, Cert (Endo), MSc, for her help during the data collection, and Prof. Nahid Ashri, BDS, Cert (Perio), MSc, for her feedback during the writing of the manuscript. In addition, the author would like to thank Markus Burkhart, SCANCO Medical AG, Fabrikweg 2 $\mathrm{CH}-8306$ Bruettisellen, Switzerland, for performing a pilot micro-CT analysis.

\section{Funding}

The work was supported by College of Dentistry, King Saud University, Riyadh, Saudi Arabia.

\section{Availability of data and materials}

complete data is available at https://figshare.com/s/0b3262687bb56ca50912.

\section{Author's contribution}

The study idea, design, data collection and manuscript writing was done by Reem Alsulaimani.

\section{Competing interest}

The author declares that she has no competing interests.

\section{Consent for publication}

not applicable

\section{Ethics approval and consent to participate}

The study protocol was approved by the Institutional Review Board and Ethical Approval Committee at the College of Dentistry, King Saud University (KSU), Saudi Arabia (FR 0235) and is in full accordance with the World Medical Association Declaration of Helsinki (version 2008). The study objectives and duration were thoroughly discussed with eligible patients, and written informed consent was obtained. Exclusion criteria included mobility grade III, according to Miller classification, and non-restorable teeth (Fig. 1a).

\section{Informed consent}

For this study, formal consent was obtained.

Received: 28 February 2016 Accepted: 12 August 2016 Published online: 23 August 2016

\section{References}

1. Glickman GN. AAE consensus conference on diagnostic terminology: background and perspectives. J Endod. 2009;35(12):1619-20. doi:10.1016/j. joen.2009.09.029.
2. Slutzky-Goldberg I, Tsesis I, Slutzky H, Heling I. Odontogenic sinus tracts: a cohort study. Quintessence Int. 2009:40:13-8.

3. Gupta R, Hasselgren G. Prevalence of odontogenic sinus tracts in patients referred for endodontic therapy. J Endod. 2003;29(12):798-800.

4. Bhaskar SN. Bone lesions of endodontic origin. Dent Clin North Am 1967:521-33.

5. Sommer R, Ostrander F, Crowley M. Clinical Endodontics. Philadelphia: W. B. Saunders Co; 1956

6. Kelly WH, Ellinger RF. Pulpal-periradicular pathosis causing sinus tract formation through the periodontal ligament of adjacent teeth. J Endod. 1988;14:251-7.

7. Stromberg T, Hasselgren G, Bergstedt $\mathrm{H}$. Endodontic treatment of resorbtive peripical osteitis with fistula. A clinical and roentgenological follow-up study. Sven Tandlak Tidskr. 1972;65(9):467-74.

8. Satish Kumar K, Subbiya A, Vivekanandhan P, Prakash V, Tamilselvi R Management of an endodontic infection with an extra oral sinus tract in a single visit: a case report. JCDR. 2013;7(6):1247-9. doi:10.7860/JCDR/2013/ 5369.3064.

9. Gupta R, Prakash V. Non-surgical management of mandibular molar with multiple intra-oral sinus tracts: a case report. JCDR. 2013;7(10):2392-3.

10. Tai T-F, Huang $S-H$, Lin $C-P$, Tsai $Y-L$, Jeng J-H. Sinus tracts from proximal roots with infected root canals: cases report. J Dent Sci. 2006;1(4):5.

11. Bergenholtz G, Horsted-Bindslev P, Reit C. Textbook of Endodontology, 2nd ed. Wiley-Blackwell; 2009.

12. ØRstavik DAG. Materials used for root canal obturation: technical, biological and clinical testing. Endod Top. 2005;12:25-38. doi:10.1111/j.1601-1546.2005. 00197.x.

13. Agrafioti A, Tzimpoulas N, Chatzitheodoridis E, Kontakiotis EG. Comparative evaluation of sealing ability and microstructure of MTA and Biodentine after exposure to different environments. Clin Oral Investig. 2015. doi:10.1007/ s00784-015-1638-6.

14. Torabinejad M, Parirokh M. Mineral trioxide aggregate: a comprehensive literature review-part II: leakage and biocompatibility investigations. J Endod. 2010;36(2):190-202. doi:10.1016/j.joen.2009.09.010.

15. von Arx T, Jensen SS, Hanni S, Friedman S. Five-year longitudinal assessment of the prognosis of apical microsurgery. J Endod. 2012:38:570-9. doi:10.1016/j.joen.2012.02.002.

16. Ricucci D, Lin LM, Spangberg LS. Wound healing of apical tissues after root canal therapy: a long-term clinical, radiographic, and histopathologic observation study. Oral Surg Oral Med Oral Pathol Oral Radiol Endod. 2009; 108(4):609-21. doi:10.1016/j.tripleo.2009.05.028

17. Friedman S, Mor C. The success of endodontic therapy-healing and functionality. J Calif Dent Assoc. 2004;32(6):493-503.

18. Valderhaug J. A histologic study of experimentally produced intra-oral odontogenic fistulae in monkeys. Int J Oral Surg. 1973;2(2):54-61. http://dx. doi.org/j.dental.2004.05.010/S0300-9785(73)80003-1.

19. Baumgartner JC, Picket AB, Muller JT. Microscopic examination of oral sinus tracts and their associated periapical lesions. J Endod. 1984;10:146-52.

20. Balto K. Trial suggests no difference between single-visit and two-visit root canal treatment. Evid-based Dent. 2013;14(2):48. doi:10.1038/sj.ebd.6400933.

21. Paredes-Vieyra J, Enriquez FJ. Success rate of single- versus two-visit root canal treatment of teeth with apical periodontitis: a randomized controlled trial. J Endod. 2012;38(9):1164-9. doi:10.1016/j.joen.2012.05.021.

22. Vela KC, Walton RE, Trope M, Windschitl P, Caplan DJ. Patient preferences regarding 1-visit versus 2-visit root canal therapy. J Endod. 2012;38:1322-5. doi:10.1016/j.joen.2012.06.038.

23. Burry JC, Stover S, Eichmiller F, Bhagavatula P. Outcomes of primary endodontic therapy provided by endodontic specialists compared with other providers. J Endod. 2016:42(5):702-5. doi:10.1016/j.joen.2016.02.008.

24. Camilleri J, Montesin FE, Brady K, Sweeney R, Curtis RV, Ford TR. The constitution of mineral trioxide aggregate. Dent Mater. 2005;21(4):297-303. doi:10.1016/j.dental.2004.05.010.

25. Islam I, Chng HK, Yap AU. Comparison of the physical and mechanical properties of MTA and portland cement. J Endod. 2006:32:193-7. doi:10.1016/j.joen.2005.10.043.

26. Boutsioukis C, Noula G, Lambrianidis T. Ex vivo study of the efficiency of two techniques for the removal of mineral trioxide aggregate used as a root canal filling material. J Endod. 2008;34(10):1239-42. doi:10.1016/j.joen. 2008.07.018.

27. Hook D, Fishelberg G. The use of gutta-percha for obturation during root canal therapy in latex-allergic patients. Gen Dent. 2003;51(4):337-9. 
28. Martin RL, Monticelli F, Brackett WW, Loushine RJ, Rockman RA, Ferrari M, et al. Sealing properties of mineral trioxide aggregate orthograde apical plugs and root fillings in an in vitro apexification model. J Endod. 2007;33:272-5.

29. Whitworth J. Methods of filling root canals: principles and practices. Endod Top. 2005;12:2-24. doi:10.1111/j.1601-1546.2005.00198.x.

30. Yeung P, Liewehr FR, Moon PC. A quantitative comparison of the fill density of MTA produced by Two placement techniques. J Endod. 2006;32:456-9.

31. Bogen $\mathrm{G}$, Kuttler $\mathrm{S}$. Mineral trioxide aggregate obturation: a review and case series. J Endod. 2009;35(6):777-90. doi:10.1016/j.joen.2009.03.006.

32. Wahengbam B, Wahengbam P, Tikku AP. A simplified technique of orthograde MTA obturation on the elected canals of posterior teeth: Two case reports. J Conserv Dent. 2014;17:80-4. doi:10.4103/0972-0707.124159.

33. Fridland M, Rosado R. Mineral trioxide aggregate (MTA) solubility and porosity with different water-to-powder ratios. J Endod. 2003;29(12):814-7. doi:10.1097/00004770-200312000-00007.

34. Marciano MA, Duarte MA, Camilleri J. Dental discoloration caused by bismuth oxide in MTA in the presence of sodium hypochlorite. Clin Oral Investig. 2015. doi:10.1007/s00784-015-1466-8.

35. Yildirim T, Er K, Tasdemir T, Tahan E, Buruk K, Serper A. Effect of smear layer and root-end cavity thickness on apical sealing ability of MTA as a root-end filling material: a bacterial leakage study. Oral Surg Oral Med Oral Pathol Oral Radiol Endod. 2010;109(1):e67-72. doi:10.1016/j.tripleo.2009.08.030.

36. Yan P, Peng B, Fan B, Fan M, Bian Z. The effects of sodium hypochlorite (5.25\%), Chlorhexidine (2\%), and Glyde File Prep on the bond strength of MTA-dentin. J Endod. 2006;32(1):58-60. doi:10.1016/j.joen.2005.10.016.

37. Pinchi V, Pradella F, Gasparetto L, Norelli GA. Trends in endodontic claims in Italy. Int Dent J. 2013;63(1):43-8. doi:10.1002/idj.12004.

38. Givol N, Rosen E, Bjorndal L, Taschieri S, Ofec R, Tsesis I. Medico-legal aspects of altered sensation following endodontic treatment: a retrospective case series. Oral Surg Oral Med Oral Pathol Oral Radiol Endod. 2011;112(1):126-31. doi:10.1016/j.tripleo.2011.01.007.

39. Gorni FG, Gagliani MM. The outcome of endodontic retreatment: a 2-yr follow-up. J Endod. 2004;30:1-4. doi:10.1097/00004770-200401000-00001.

40. Estrela C, Bueno MR, Leles CR, Azevedo B, Azevedo JR. Accuracy of cone beam computed tomography and panoramic and periapical radiography for detection of apical periodontitis. J Endod. 2008;34:273-9. doi:10.1016/j. joen.2007.11.023.

\section{Submit your next manuscript to BioMed Central and we will help you at every step:}

- We accept pre-submission inquiries

- Our selector tool helps you to find the most relevant journal

- We provide round the clock customer support

- Convenient online submission

- Thorough peer review

- Inclusion in PubMed and all major indexing services

- Maximum visibility for your research

Submit your manuscript at www.biomedcentral.com/submit

) Biomed Central 